\title{
ANTHRAQUINONES PRODUCTION IN AERIAL PARTS-DERIVED CALLUS OF RUBIA TINCTORUM L.
}

\author{
A. M. A. Abd El-Mawla, E. Y. Backheet and N. A. El-Emary
}

Department of Pharmacognosy, Faculty of Pharmacy, Assiut University, Assiut, Egypt

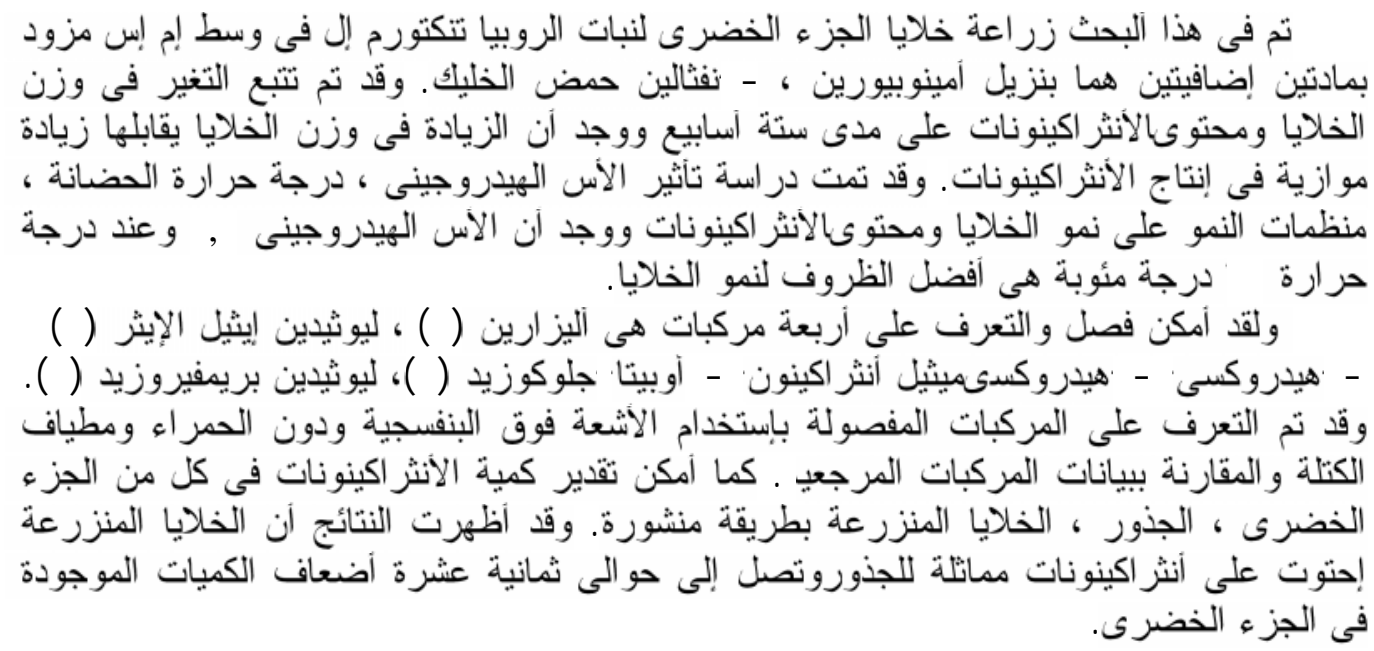

Callus cultures were developed from the aerial parts of Rubia tinctorum L. on MS medium containing 6-benzylaminopurine and 1-naphthaleneacetic acid. The changes in callus weight and anthraquinones content were followed between week 1 and 6. Anthraquinones content was monitored by HPLC. The linear increase in fresh weight was found to be parallel to the anthraquinones production. Effect of medium $\mathrm{pH}$, incubation temperature and growth regulators on callus growth and anthraquinones content was studied and optimised. $p H 7.5$ and temperature of $30^{\circ}$ were found optimum for the callus growth. 6-Benzylaminopurine $(0.5 \mathrm{mg} / \mathrm{L})$ and 1-naphthaleneacetic acid $(2.0 \mathrm{mg} / \mathrm{L})$ were found the most appropriate growth regulators.

The callus ethanolic extract showed the same picture on TLC as that of the roots. The anthraquinones alizarin (1), lucidin-w-ethyl ether (2), 1-hydroxy-2-hydroxymethylantraquinone-3-O- $\beta$-glucoside (3) and lucidin primeveroside (4) in addition to other four minor anthraquinone spots were found to be produced by these cultures. The four isolated compounds (1-4) were identified by spectral analysis (UV, IR and MS) as well as comparison with authentic samples. Aerial parts, roots and the callus were analysed for their anthraquinones content. The anthraquinones content of callus extract was about $91 \%$ and eighteen fold of the roots and aerial parts extract respectively.

\section{INTRODUCTION}

Rubia tinctorum L. (dyer's madder), ${ }^{1}$ Family Rubiaceae, is a perennial herbaceous plant having long fleshy roots which furnish a dye. It was used as diuretic, astringent, as remedy in liver disease and spleen complaints. ${ }^{2}$ The roots extract was used for the treatment of kidney, bladder stones ${ }^{3}$ and contains substantial amounts of anthraquinones. ${ }^{4-6}$ The presence of minor biologically active anthraquinones in the aerial parts of this plant $^{7}$ has served as an incentive for the development of cell cultures capable of long-term cultivation and synthesis of secondary metabolities. In the present work, we study the effect of growth regulators on the developing callus cultures from the aerial parts of $R$. tinctorum L. as an alternative source of anthraquinones. 


\section{EXPERIMENTAL}

\section{Materials}

Apparatus

1- Uvidec-320 spectrophotmeter with matched $1 \mathrm{~cm}$ quartz cells, (Jasco, Tokyo, Japan).

2- Schimadzu Infra red-470 Spectrometer (Tokyo, Japan).

3- $\mathrm{EI}^{+}$- and FAB-MS spectra were recorded by JEOL, JMS 600 H, Japan.

4- HPLC, Knauer, Germany.

5- UV-Lamp (Marine Lavalee-Cedex, France).

6- Incubator, Gallenkamp, England.

\section{Reagents}

- 5\% alcoholic potassium hydroxide.

- ammonia vapours.

\section{Solvent systems}

I- n-Hexane - ethyl acetate (90:10).

II- n-Hexane - ethyl acetate (80:20).

III- Chloroform - methanol (80:20).

IV- Chloroform - methanol (70:30).

\section{Chemicals}

Silica gel for column, precoated silica gel plates $60 \mathrm{~F}_{254}$ (E. Merck, Germany). 6-Benzylaminopurine, 1-naphthaleneacetic acid (NAA), 6-furfurylaminopurine, 3,6-dichloro-2methoxy-benzoic acid and 2,4-dichlorophenoxyacetic acid were obtained from E. Merck, Darmstadt, Germany.

\section{Plant material}

Aerial parts of $R$. tinctorum L. were collected in January 2002 (before flowering) from the plant cultivated in the Experimental Station, Faculty of Pharmacy, Assiut University, were used as explant sources.

\section{Method \\ Callus culture induction and development \\ Leaves and young stems of $R$. tinctorum L. were used as explant sources. After rinsing in water, explants were sterilized with $70 \%$ ethanol for few seconds, immersed in a $0.1 \%$ solution of mercuric chloride ${ }^{8}$ for 15 minutes and washed three times with sterile distilled water. They were then cultured in the dark at $30^{\circ}$ in $300-\mathrm{ml}$ flasks containing $50 \mathrm{ml}$ of MS medium $^{9}$ containing both $0.5 \mathrm{mg} / \mathrm{L} \quad 6-$ benzylaminopurine and $2.0 \mathrm{mg} / \mathrm{L} \quad 1-$ naphthaleneacetic acid. ${ }^{10}$ Callus emerging on}

the explants (after 3 weeks) was excised and cultivated on the same medium at $30^{\circ}$ for 3 weeks periods.

To select high-producing callus cultures, the deeper coloured small cell aggregates were isolated from the stock yellow callus and further subcultured on the same medium for another 3-weeks periods. Callus tissues of these selected strains were subcultured for a further 6-weeks before they were characterized quantitatively for pigment content.

\section{Growth curves and anthraquinones content}

The changes in fresh callus weight and anthraquinones content of cell cultures were followed by using ten flasks with $100 \mathrm{ml}$ fresh MS medium and inoculated with $1 \mathrm{~g}$ callus cells (week zero) grown in the dark. Fresh callus weight and anthraquinones content were determined from week zero to week 6 at one week intervals by HPLC method, Figure 1 .

\section{HPLC method}

It is used for the determination of anthraquinones in the study of each of the effect of $\mathrm{pH}$, incubation temperature as well as the effect of growth regulators on the anthraquinones production.

The callus was dried under hot air flow and powdered, $5 \mathrm{~g}$ quantity was extracted exhaustively on cold with $50 \mathrm{ml}$ of $70 \%$ ethanol for 3 hours. Extracts were filtered through filter paper and the filtrate was evaporated under reduced pressure at $40^{\circ}$. The residue was dissolved in $1 \mathrm{ml}$ methanol and subjected to HPLC analysis. Elution was carried out with water-methanol (20-70\%) in a Nucleosil 100-5 $\mathrm{C}_{18}$ column (Macherey-Nagel) at a flow rate of $1 \mathrm{ml} /$ minute, and the detection wavelength set to $246 \mathrm{~nm}$. Identification of anthraquinones was achieved from the retention time values. The area under the curves corresponding for the major compounds were used to calculate the anthraquinones content. $^{8,11}$ The results were calculated as alizarin.

Study of the effect of medium $\mathrm{pH}$ and incubation temperature on callus growth and anthraquinones content

The optimum $\mathrm{pH}$ and temperature for callus growth and anthraquinones content were studied by using a series of 100-ml flasks 
inoculated with $1 \mathrm{~g}$ cultured cells grown in MS medium at different $\mathrm{pH}$ values between 6.0 and 9.0 in the dark for a period of 4 weeks. At the optimum $\mathrm{pH}$ value another series of inoculations were performed at different temperatures between 20 and $45^{\circ}$. The results are shown in Tables 1 and 2.

\section{Effect of growth regulators on callus growth and anthraquinones content}

At the optimum $\mathrm{pH}$ and incubation temperature, series of experiments were performed using different types of growth regulators at different concentrations (ranging from $0.3-4.0 \mathrm{mg} / \mathrm{L}$ ) in the dark for a period of 4 weeks. Each two growth regulators were used together as follows: 6-Benzylaminopurine with 1-naphthaleneacetic acid, 6-furfurylaminopurine with 1-naphthaleneacetic acid, 6furfurylaminopurine with 3,6-dichloro-2methoxy-benzoic acid and 6-Benzylaminopurine with 2,4-dichloro-phenoxyacetic acid.

Determination of anthraquinones in the aerial parts, roots and callus by the reported colorimetric procedure ${ }^{7,12}$

Five grams of aerial parts, roots and callus were accurately weighed and separately transferred to 250-ml flasks, each sample was extracted by refluxing five times with $30 \mathrm{ml}$ of $70 \%$ ethanol containing $1 \%$ hydrochloric acid on a boiling water bath until the alcohol gave no red colour with potassium hydroxide (T.S.). The combined alcohol extracts were filtered and transferred to a volumetric flask $(250 \mathrm{ml})$. The volumes were then adjusted with ethanol $70 \%$. To $20 \mathrm{ml}$ of each solution, $10 \mathrm{ml}$ of concentrated hydrochloric acid was added, the mixture was heated on a boiling water bath under reflux for 15 minutes, cooled and extracted with several successive portions of ether. The combined ether extracts were washed with $20 \mathrm{ml}$ of water and the washing was rejected. The ether containing free anthraquinones was completed to $100 \mathrm{ml}$ in a volumetric flask, $10 \mathrm{ml}$ of the ether solution was extracted with known volume of $1 \mathrm{~N}$ sodium hydroxide and the developed colour in each case was measured colorimetrically within one hour. The concentration of total anthraquinones in each sample was calculated as alizarine from the calibration curve. Results were listed in Table 3.

\section{Extraction and isolation of anthraquinones}

Fifty grams of dried, ground callus of $R$. tinctorum L. were exhaustively extracted with $70 \%$ ethanol, concentrated under reduced pressure and the concentrate (4.5 g) was subjected to solvent fractionation using nhexane $(2 \times 150 \mathrm{ml})$, ethyl acetate $(2 \times 150 \mathrm{ml})$ and n-butanol $(2 \times 200 \mathrm{ml})$ respectively. The obtained fractions were separately concentrated and screened by TLC for different constituents.

\section{A- n-Hexane fraction}

The n-hexane soluble fraction was chromatographed on silica gel column, elution was started with $\mathrm{n}$-hexane followed by $\mathrm{n}$ hexane/ethyl acetate gradient. Fractions eluted with n-hexane/ethyl acetate (90:10) afforded compounds $\mathbf{1}$ and $\mathbf{2}$.

\section{B- Ethyl acetate fraction}

The ethyl acetate soluble fraction was chromatographed on silica gel column. Elution was started with chloroform followed by chloroform/ methanol gradient, similar fractions were combined and concentrated. Fractions eluted with chloroform/methanol (85:15) afforded compound (3) and fractions eluted with chloroform-methanol (80:20) gave mixture of two minor anthraquinones spots.

\section{C- n-Butanol fraction}

The n-butanol soluble fraction was chromatographed on silica gel column. Elution was started with ethyl acetate followed by ethyl acetate/methanol gradient, similar fractions were combined and concentrated. Fractions eluted with ethyl acetate/methanol (85:15) yielded compound (4) and fractions eluted with ethyl acetate-methanol (80:20) gave two minor anthraquinones spots.

\section{Compound 1}

Red purple crystals (10 mg), IR (KBr, v, $\left.\mathrm{cm}^{-1}\right): 3340,1585,1660$ and 1625 , UV $\left(\lambda_{\max }\right.$, $\mathrm{nm}, \mathrm{EtOH}): 248,263,275$ and 430. $\mathrm{EI}^{+}$-MS at $\mathrm{m} / \mathrm{z}=240(100 \%)[\mathrm{M}]^{+}$, other diagnostic peaks at $m / z=241(21.5 \%)[\mathrm{M}+1]^{+}, 212(32.4 \%)$, $184(23.5 \%), 138(33.1 \%), 128(31.5 \%)$ and 77 $(22.3 \%)$. 
<smiles>[R2]c1cc2c(c(O)c1[R])C(=O)c1ccccc1C2=O</smiles>

$\begin{array}{ccl}\text { Compd. } & \mathrm{R}_{1} & \mathrm{R}_{2} \\ \mathbf{1} & \mathrm{OH} & \mathrm{H} \\ \mathbf{2} & \mathrm{CH}_{2} \mathrm{OCH}_{2} \mathrm{CH}_{3} & \mathrm{OH} \\ \mathbf{3} & \mathrm{CH}_{2} \mathrm{OH} & \text { O-glucose } \\ \mathbf{4} & \mathrm{CH}_{2} \mathrm{OH} & \text { O-glucose(6-1)xylose }\end{array}$

\section{Compound 2}

Yellow crystalline needles (7 mg), IR $\left(\mathrm{KBr}, v, \mathrm{~cm}^{-1}\right): 3210,1675,1630,1590$ and 1280, UV ( $\left.\lambda_{\max }, \mathrm{nm}, \mathrm{EtOH}\right): 246,281$ and 418. $\mathrm{EI}^{+}$-MS at $m / z=298(7.4 \%)[\mathrm{M}]^{+}, 252(100 \%)$ $\left[\mathrm{M}-\mathrm{CH}_{3} \mathrm{CH}_{2} \mathrm{OH}\right]^{+}$, other diagnostic peaks at $\mathrm{m} / \mathrm{z}=253(19.2 \%), 255$ (3.1\%), $224(11.2 \%)$, $196(30.3 \%), 139(31.4 \%)$, and $77(7.0 \%)$.

\section{Compound 3}

Yellow powder $(10 \mathrm{mg}), \mathrm{IR}\left(\mathrm{KBr}, v, \mathrm{~cm}^{-}\right.$ $\left.{ }^{1}\right)$ : 3415, 1655, 1621, 1578, 1474 and 1287, UV $\left(\lambda_{\max }, \mathrm{nm}, \mathrm{MeOH}\right): 244,266,333$ and 404. FAB-MS at $m / z=433\left[\mathrm{M}+1^{+}\right](8.8 \%), 271$ (20.4\%), $255(25.5 \%), 254(12.3 \%), 253$ (40.4\%), 225 (33\%), 197 (37.7\%), 169 (32.9\%) and $139(48.1 \%)$.

\section{Compound 4}

Yellow powder $(30 \mathrm{mg}), \mathrm{IR}\left(\mathrm{KBr}, v, \mathrm{~cm}^{-}\right.$ $\left.{ }^{1}\right)$ : 3390, 1665, 1622, 1585, 1366 and 1286, UV $\left(\lambda_{\max }, \mathrm{nm}, \mathrm{MeOH}\right): 244,266,333$ and 404. FAB-MS at $m / z=565\left[\mathrm{M}+1^{+}\right](1.1 \%), 434$ (7.6\%), 271 (9.2\%), 255 (24\%), 254 (51.9\%), $225(15 \%), 197(10.6 \%), 169(9.6 \%)$ and 139 $(20.7 \%)$.

\section{RESULTS AND DISCUSSION}

The leaves and young stems of $R$. tinctorum L. were used to establish callus cultures. After the third subculture, callus appeared as a yellow stock with brown coloured small cell aggregates which were isolated and further subcultured. The production of anthraquinones in callus extract was evidenced by their red coloured spots on TLC with $5 \%$ alcoholic potassuium hydroxide or ammonia vapours.
The growth of the callus in MS medium was characterized in the dark. ${ }^{10}$ Figure 1 showed an increase in fresh weight between week 1 and week 6 after inoculation of cells into fresh medium. The increase in fresh weight was found to be parallel to anthraquinones accumulation.

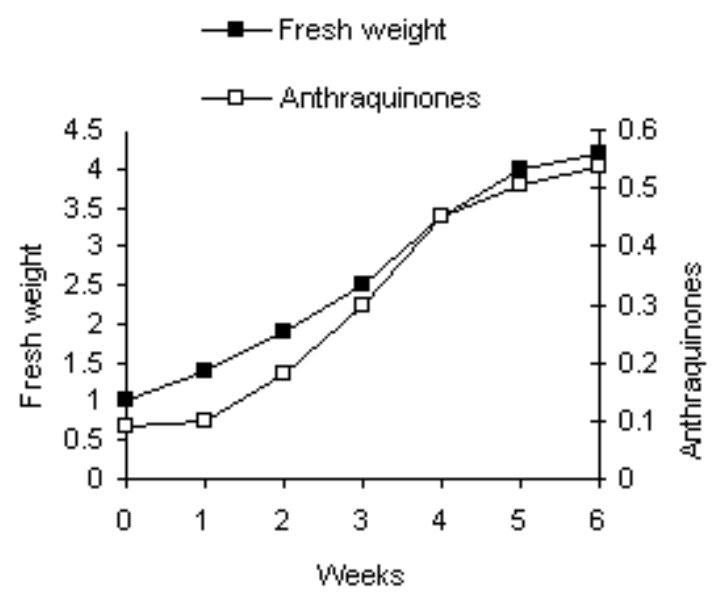

Fig. 1: Changes in fresh weight and anthraquinones content of $R$. tinctorum $\mathrm{L}$. cell cultures.

* The data are mean values of three independent experiments.

Study of the effect of medium $\mathrm{pH}$ and incubation temperature on callus growth and anthraquinones accumulation revealed that the highest callus growth and anthraquinones production was obtained at $\mathrm{pH} 7.5$ and an incubation temperature of $30^{\circ}$. The results were listed in Tables 1 and 2.

The anthraquinones content in root, callus (4 weeks old) and aerial parts extracts were compared using the reported colorimetric procedure which depends on the reaction with sodium hydroxide. ${ }^{7,12}$ The results showed that, the aerial parts extract contain low amount of anthraquinones. The callus extract was found to contain about $91 \%$ of the anthraquinones content of the roots extract and about eighteen fold of aerial parts extract. Results were listed in Table 3.

The influence of some growth regulators on biomass accumulation and anthraquinones production by $R$. tinctorum $\mathrm{L}$. callus cultures was tested. 6-Benzylaminopurine and 1naphthaleneacetic acid, which have been reported to be appropriate regulators, supporting high level of anthraquinones accumulation in $R$. cordifolia $\mathrm{L}$. callus 
Table 1: Effect of medium $\mathrm{pH}$ on callus fresh weight and anthraquinones content.

\begin{tabular}{|c|c|c|}
\hline Medium $\mathrm{pH}$ & $\begin{array}{c}\text { Callus fresh weight }(\mathrm{g})^{*}, \\
\pm \mathrm{SD}\end{array}$ & $\begin{array}{c}\text { Anthraquinones }(\%)^{*}, \\
\pm \mathrm{SD}\end{array}$ \\
\hline 6.0 & $1.60 \pm 0.041$ & $1.45 \pm 0.034$ \\
\hline 6.5 & $2.10 \pm 0.046$ & $1.60 \pm 0.039$ \\
\hline 7.0 & $2.70 \pm 0.052$ & $1.85 \pm 0.040$ \\
\hline 7.5 & $3.12 \pm 0.064$ & $2.16 \pm 0.045$ \\
\hline 8.0 & $2.85 \pm 0.059$ & $1.90 \pm 0.040$ \\
\hline 8.5 & $2.40 \pm 0.053$ & $1.65 \pm 0.035$ \\
\hline 9.0 & $1.90 \pm 0.039$ & $1.33 \pm 0.030$ \\
\hline
\end{tabular}

* The data are mean values of three independent experiments.

Table 2: Effect of incubation temperature on callus fresh weight and anthraquinones content.

\begin{tabular}{|c|c|c|}
\hline $\begin{array}{c}\text { Incubation } \\
\text { Temperature }\left({ }^{\circ} \mathrm{C}\right)\end{array}$ & $\begin{array}{c}\text { Callus fresh weight } \\
(\mathrm{g}) * \pm \mathrm{SD}\end{array}$ & $\begin{array}{c}\text { Anthraquinones content } \\
(\%)^{*}, \pm \mathrm{SD}\end{array}$ \\
\hline 20 & $2.40 \pm 0.050$ & $1.30 \pm 0.034$ \\
\hline 25 & $3.00 \pm 0.058$ & $1.90 \pm 0.041$ \\
\hline 30 & $3.40 \pm 0.075$ & $2.20 \pm 0.043$ \\
\hline 35 & $2.90 \pm 0.059$ & $1.80 \pm 0.017$ \\
\hline 40 & $2.30 \pm 0.047$ & $1.40 \pm 0.035$ \\
\hline 45 & $1.70 \pm 0.033$ & $0.90 \pm 0.019$ \\
\hline
\end{tabular}

*The data are mean values of three independent experiments.

Table 3: Determination of anthraquinones in the aerial parts, roots and callus extracts by the reported colorimetric procedure ${ }^{7,12}$.

\begin{tabular}{||c|c|c|}
\hline \multirow{2}{*}{ Extract } & \multicolumn{2}{|c|}{ Anthraquinones (\%) } \\
\cline { 2 - 3 } & Found, \pm SD & Reported $^{7}$ \\
\hline Aerial parts & $0.13 \pm 0.002$ & 0.16 \\
\hline Roots & $2.53 \pm 0.056$ & 2.90 \\
\hline Callus & $2.30 \pm 0.043$ & ----- \\
\hline
\end{tabular}

* The data are mean values of three independent experiments. 
Table 4: The effect of growth regulators on anthraquinones content in $R$. tinctorum L. callus cultures.

\begin{tabular}{||l|c|c|}
\hline \multicolumn{2}{|c|}{ Growth regulators } & $\begin{array}{c}\text { Anthraquinones (\%)* } \\
\pm \mathrm{SD}\end{array}$ \\
\cline { 1 - 2 } Name & Concentration, mg/L & $2.13 \pm 0.048$ \\
\hline 6-Benzylaminopurine and & 0.5 & $2.09 \pm 0.044$ \\
1-Naphthaleneacetic acid & 2.0 & $2.11 \pm 0.050$ \\
6-Furfurylaminopurine and & 0.5 & \\
1-Naphthaleneacetic acid & 0.0 & $1.10 \pm 0.021$ \\
6-Furfurylaminopurine and & 2.0 & \\
3,6-Dichloro-2-methoxy- & 0.5 & \\
benzoic acid & 2.0 & \\
\hline 6-Benzylaminopurine and & & \\
2,4-Dichlorophenoxyacetic acid & & \\
\hline
\end{tabular}

* The data are mean values of three independent experiments.

cultures, ${ }^{10}$ were found to be the best effective regulators for the stimulation of anthraquinones production in our cultures.

Results of the effect of plant growth regulators on anthraquinones production from $R$. tinctorum L. callus were listed in Table 4.

The callus extract showed the same picture on TLC as that of the roots. The isolated anthraquinones were identified as alizarin (1), lucidin- $\omega$-ethyl ether (2), 1hydroxy-2-hydroxymethylanthraquinone-3-O$\beta$-glucoside (3) and lucidin primeveroside (4) from their UV, IR, MS spectral data, cochromatography with authentic samples and comparison with reported data. ${ }^{4,5}$

In conclusion, The callus extract of the aerial parts of $R$. tinctorum $\mathrm{L}$. was found to contain about $91 \%$ of the anthraquinones content of the roots extract and about eighteen fold of aerial parts extract.

They were found to be of the same type as the roots, which can be offered as an alternative source of anthraquinones.

\section{REFERENCES}

1- L. H. Baily, Manual of Cultivated Plants, $4^{\text {th }}$ edn. The MacMillan Co., New York. Vol. 11, p. 925 (1958).

2- K. R. Kirtikar and B. D. Basu, , Indian Medicinal Plants, vol. II, $2^{\text {nd }}$ edn., M/S Bishen Singh, Mahender Pal Singh, Periodical Express (1975).
3- J. Westendorf (Ed), P. A. G. M. Smet, K. Keller, R. Hansel, R. F. Chandler, Adverse Effects of Herbal Drugs, Springer-Verlag, Berlin, Heidelberg, Vol. 2, p. 137-139 (1993).

4- R. A. Hill, H. Chr. Krebs, R. Verpoorte and R. Wijnsma, Progress in the Chemistry of Organic Natural Products, Springer-Verlag, Wein, New York, Vol. 49, p. 78-149 (1986).

5- N. A. El-Emary and E. Y. Backheet, Phytochemistry, 49, 277-279 (1998).

6- E. Y. Backheet, S. F. Farag and N. A. ElEmary, Bull. Fac. Pharm. Cairo Univ., 39, 135-139 (2001).

7- R. H. El-Sofany. M.Sc. Thesis, Faculty of Pharmacy, Cairo University (1980).

8- W. Schmidt, Ph. D. Dissertation, Bonn, Germany (1997).

9- T. Murashige and F. Skoog, Physiol. Plant., 15, 473 (1962).

10- N. P. Mischenko, S. A. Fedoreyev, V. P. Glazunov, G. K. Chernoded, V. P. Bulgakov and Y. N. Zhuravlev, Fitoterapia, 70, 552-557 (1999).

11- A. M. A. Abd El-Mawla, Ph.D. Dissertation, Bonn, Germany (2001).

12- J. W. Fairbairin and G. E. D. H. Mahran, J. Pharm. Pharmacol., 5, 827-835 (1953). 